\title{
The RHOMOLO Spatial CGE Model
}

\author{
Martin Aarøe Christensen
}

\subsection{INTRODUCTION}

RHOMOLO is the dynamic Spatial Computable General Equilibrium (CGE) model of the European Commission. It is developed and maintained by the Joint Research Centre (JRC) and used for policy impact assessment and for sector-, region- and time-specific model-based support to EU policymakers on structural reforms, growth and cohesion policies, including $\mathrm{R} \& \mathrm{D}$ support programmes.

The objective of RHOMOLO is to allow for the analysis of EU policies at the regional NUTS 2 level. Given the regional focus of RHOMOLO, a particular attention is devoted to the explicit modelling of spatial linkages, interactions and spillovers between regional economies. The model aims to account for local specificities which may affect the dynamics of

The views expressed are purely those of the author and may not in any circumstances be regarded as stating an official position of the European Commission.

M. A. Christensen $(\varangle)$

European Commission, DG JRC, Seville, Spain

e-mail: Martin.Christensen@ec.europe.eu

(C) The Author(s) 2022

U. Akcigit et al. (eds.), Macroeconomic Modelling of R\&D

and Innovation Policies, International Economic Association Series, https://doi.org/10.1007/978-3-030-71457-4_5 
the regional economies such as factor endowment and local geography. In addition, European regions are very open, small economies, well integrated within and across national borders. Therefore, socio-economic developments in each region may be significantly affected by policy developments in their neighbouring regions and this dimension needs to be taken into account when analysing policy scenarios. The socio-economic conditions of European territories vary substantially at a sub-national level. Figure 5.1 illustrates the divergent economic conditions across EU regions. The figure shows the regional Gross Value Added (GVA) per capita for regions at the NUTS 2 level for the year 2013 which is the reference year of the most recent version of RHOMOLO. The figure shows that substantial deviation in per capital GVA can be observed across the EU and even within the EU Member States. Across the EU a number of metropolitan regions are characterized by per capita GVA which are considerable higher than the EU average. For example the 8 regions with the highest per capita value added all have per capita GVA that are more than twice the EU average. ${ }^{1}$ Per capita GVA in Inner London is about 3.5 times the EU average and 26 times higher than in the EU region with the lowest per capita GVA which is the Bulgarian Region Severozapaden. In contrast, the 25 regions with the lowest per capita value added all have per capita GVA which is less than a third of the EU average. ${ }^{2}$ Most Member States host one or more metropolitan areas where per capita GVA is considerable higher than the national average. The eight regions which have the highest per capita value added relatively to their national average, all have per capita GVA which is more than 1.6 times their national average. ${ }^{3}$

Given the variations in socio-economic conditions across EU regions, the economic impact of EU policies in support for R\&D may also vary substantially across regions. The RHOMOLO model has been used in an attempt to capture deviations in regional outcomes of $\mathrm{R} \& \mathrm{D}$ polices. This chapter is organized as follows. The next section provides a short introduction to the current version of RHOMOLO with special emphasis

1 The 8 regions are: Inner London, Luxembourg, Stockholm, the Region of Brussels, Hamburg, Groningen, Copenhagen and Île-de-France.

2 The 25 regions mentioned are located in Poland, Romania, Hungary and Bulgaria.

3 The 8 regions are: Inner London, Bratislava, Bucharest, Prague, the Region of Brussels, Hamburg, Île-de-France, Yugozapaden (incl. Sofia). 
Fig. 5.1 Gross value added per capita across EU regions (1000 euro)

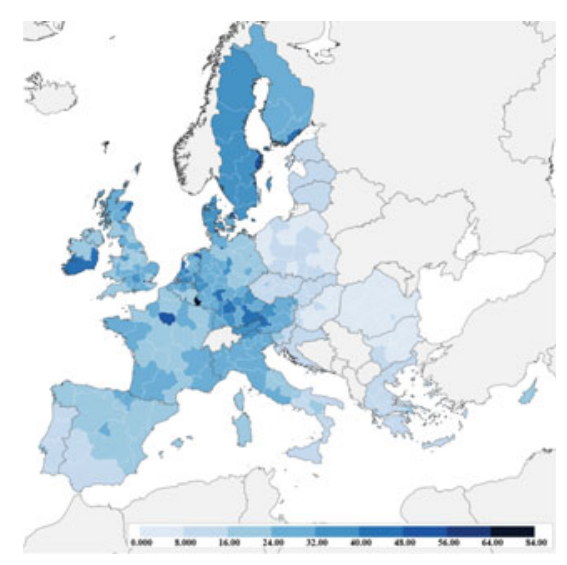

on how R\&D enters the model. It also discusses the main limitations to the treatments of $\mathrm{R} \& \mathrm{D}$ in the model and highlights some requirements which future developments of R\&D modelling in RHOMOLO should address. The last section contains a discussion of scenarios and findings following the economic impact assessment exercise of the Horizon Europe Framework Programme for Research and Innovation.

\subsection{The Model}

RHOMOLO is a Spatial Dynamic General Equilibrium model with new economic geography features. ${ }^{4}$ The model contains a detailed specification of 267 regional economies and their spatial interactions.

Each region contains 10 economic sectors: Agriculture, Forestry and Fishing; Mining, Quarrying and Utilities ${ }^{5}$; Manufacturing; Construction; Whole and Retail Trade; Information and Communication; Financial, Insurance and Real Estate Activities; Professional, Scientific and Technical Activities; Public administration, Education, Health and Social Services; Other Services. A subset of these operates under monopolistic competition. The rest of the sectors operate under perfect competition. In the

${ }^{4}$ A detailed description of the latest available version of RHOMOLO can be found in Lecca et al. (2018).

5 Here the term utilities refer to the sectors: Electricity, Gas, Steam and Air Conditioning Supply, Water Supply, waste Management and Remediation Activities. 
imperfectly competitive sectors, each firm produces a given variety of the good which is an imperfect substitute for other varieties. The variety is produced with constant returns to scale technology. In addition, the firm faces fixed costs $F C$ in the form of a fixed amount of its production which is not sold on the market. This introduces increasing returns to scale. To survive firms, in the imperfectly competitive sectors, have to charge positive mark-ups over marginal costs. These mark-ups are determined by the properties of the demand curve these firms face. We assume that there are free entry and exit of firm. Hence, given fixed costs and substitutability between goods the number of firms operating within a sector in a region are endogenously given to ensure that the zero profit condition holds. Firms in the perfectly competitive sectors have constant returns to scale technologies, minimize costs and are constrained to marginal costs pricing.

In all regional production sectors, goods are produced by combining labour and capital with domestic and imported intermediates, creating vertical linkages between firms. The production structure is given by a nested CES production function as shown in Fig. 5.2.

For a firm in sector $i$ in region $r$, the demand for intermediate input $V_{r, i}$ and value added $Y_{r, i}$ in the upper nest of the production function is

Fig. 5.2 Production structure

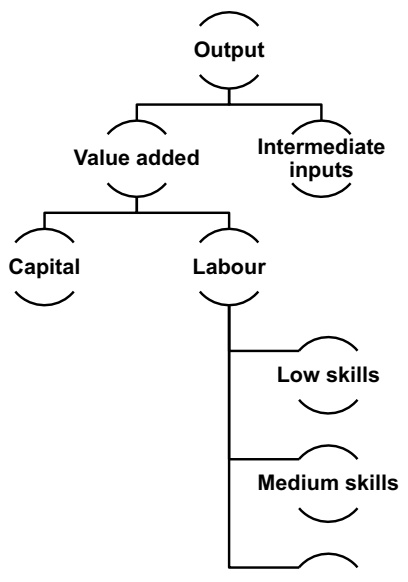

High Skills

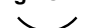


given by

$$
\begin{aligned}
& V_{r, i}=\frac{\alpha_{r, i}^{z}}{\left(A x_{r, i}\right)^{1-\sigma^{z}}}\left[\frac{P_{r, i}^{v}}{P_{r, i}^{z}}\right]^{-\sigma^{z}}\left(Z_{r, i}+F C_{r, i}\right) \\
& Y_{r, i}=\frac{\left(1-\alpha_{r, i}^{z}\right)}{\left(A x_{r, i}\right)^{1-\sigma^{z}}}\left[\frac{P_{r, i}^{y}}{P_{r, i}^{z}}\right]^{-\sigma^{z}}\left(Z_{r, i}+F C_{r, i}\right)
\end{aligned}
$$

where $\alpha_{r, i}^{z}$ is the calibrated share of intermediate inputs in total production, $A x_{r, i}$ is a scale parameter and $\sigma^{z}$ is the elasticity of substitution. The prices $P_{r, i}^{z}, P_{r, i}^{v}$ and $P_{r, i}^{y}$ is respectively the marginal production cost, the composite price index for intermediate inputs and the composite price index for value added. The marginal production cost $P_{r, i}^{z}$ is given by

$$
P_{r, i}^{z}=\frac{1}{A x_{r, i}}\left(\alpha_{r, i}^{z}\left(P_{r, i}^{v}\right)^{1-\sigma^{z}}+\left(1-\alpha_{r, i}^{z}\right)\left(P_{r, i}^{y}\right)^{1-\sigma^{z}}\right)^{\frac{1}{1-\sigma^{z}}}
$$

whereas the composite price indices are given by

$$
\begin{gathered}
P_{r, i}^{v}=\left(\sum_{j} \alpha_{r, j, i}^{v}\left(P_{r, j}\right)^{1-\sigma^{v}}\right)^{\frac{1}{1-\sigma^{v}}} \\
P_{r}^{y}=\frac{1}{\left(\varphi_{r, i}\left(K_{r}^{g, d}\right)^{\xi}\right)}\left(\alpha_{r, i}^{y}\left(r k_{r, i}\right)^{1-\sigma^{y}}+\left(1-\alpha_{r, i}^{y}\right)\left(W_{r, i}\right)^{1-\sigma^{y}}\right)^{\frac{1}{1-\sigma^{y}}}
\end{gathered}
$$

where $P_{r, j}$ is the price of the intermediate input from sector $j, r k_{r, i}$ is the return on capital, $W_{r, i}$ is a composite wage index, $\alpha_{r, j, i}^{v}$ and $\alpha_{r, i}^{y}$ are share parameters, and $\sigma^{v}$ and $\sigma^{y}$ are the elasticities of substitution for intermediate inputs and capital-labour respectively. Public capital services $K_{r}^{g, d}$ enters the production function as an unpaid factor of production meaning that all firms, in all sectors, enjoy the same level of public capital at no cost. The parameter $\varphi_{r, i}$ captures changes in total factor productivity. As discussed below, this is a key parameter for introducing long-term impacts of $\mathrm{R} \& \mathrm{D}$ in the model. Demand for capital and labour is given by

$$
K D_{r, i}=\frac{\alpha_{r, i}^{y}}{\left(\varphi_{r, i}\left(K_{r}^{g, d}\right)^{\xi}\right)^{1-\sigma^{y}}}\left[\frac{r k_{r, i}}{P_{r, i}^{y}}\right]^{-\sigma^{y}} Y_{r, i}
$$




$$
L D_{r, i}=\frac{\left(1-\alpha_{r, i}^{y}\right)}{\left(\varphi_{r, i}\left(K_{r}^{g, d}\right)^{\xi}\right)^{1-\sigma^{y}}}\left[\frac{W_{r, i}}{P_{r, i}^{y}}\right]^{-\sigma^{y}} Y_{r, i}
$$

The composite wage index $W_{r, i}$ is given by

$$
W_{r, i}=\frac{1}{A l_{r, i, e}}\left(\sum_{e} \alpha_{r, i}^{l d}\left(W_{r, i, e}\right)^{1-\sigma^{l d}}\right)^{\frac{1}{1-\sigma^{l d}}}
$$

where $A l_{r, i, e}$ is a scale parameter that captures labour productivity, $W_{r, i, e}$ is the wage for labour of skills type $e$ and $\sigma^{l d}$ is the elasticity of substitution between labour of different skills types. The firms demand for labour of skills type $e$ is

$$
L D_{r, i, e}=\frac{\alpha_{r, i, e}^{l d}}{\left(A l_{r, i, e}\right)^{1-\sigma^{l d}}}\left[\frac{W_{r, i, e}}{W_{r, i}}\right]^{-\sigma^{l d}} L D_{r, i}
$$

Final goods are consumed by households, government and investors. Each region is inhabited by a representative household which supplies labour of three skills type (high, medium and low), consume and save. The composite of household consumption is described by CES preferences. Household's demand for the composite good from sector $i$ is given by

$$
C_{r, i}=\alpha_{r, i}\left[\frac{P_{r, i}}{P_{r}^{c}}\right]^{-\sigma^{c}} C_{r}
$$

where $C_{r}$ is the aggregate composite consumption good, $\alpha_{r, i}$ is a share parameter and $\sigma^{c}$ is the elasticity of substitution. The associated consumption price index $P_{r}^{c}$ is defined in terms of prices $P_{r, i}$ of the different sector $i$ composite goods.

$$
P_{r}^{c}=\left(\sum_{i=1} \alpha_{r, i}\left(P_{r, i}\right)^{1-\sigma^{c}}\right)^{\frac{1}{1-\sigma^{c}}}
$$

The household saves a fixed share $s_{r}$ of disposable income.

$$
S_{r}=s_{r} Y D_{r}
$$


The government levies taxes, purchases public consumption goods, conducts public investments and allocates transfers to the various agents in the economy. Public consumption, public investments and transfers in real terms are exogenous to the model.

The RHOMOLO model incorporates imperfect competition in the labour market which allows for unemployment. The model allows one to switch from a wage curve assumption to a Phillips curve assumption in wage formation.

The model contains two types of capital, sector-specific private capital and public capital available to firm in all sectors within the region. Sectorspecific private capital is accumulated by private investors. The optimal path of private investments $I_{r, i}^{p}$ is defined as

$$
I_{r, i}^{p}=\delta_{r} K_{r, i}^{p}\left(\frac{r k_{r, i}}{u c k_{r}}\right)^{v}
$$

where $v$ is the accelerator parameter and $\delta$ is the depreciation rate. The investment-capital ratio is a function of the rate of return to capital and the user cost of capital $u c k_{r}$ allowing the capital stock to reach its desired level in a smooth fashion over time. The user cost of capital is derived from a no arbitrage condition and is given by

$$
u c k_{r}=\left(r+\delta_{r}\right) P_{E U}^{I}+\Delta P_{E U}^{I}+r p_{r}
$$

where $r$ is the interest rate, $r p$ is an exogenous risk premium and $P_{E U}^{I}$ is the price index for investments at the EU level. The demand for investment $I_{r, i}^{p}$ by sector $i$ is translated into demand for investments goods through a capital matrix

$$
I_{r, j}^{s}=\sum_{i} K M_{r, i, j} I_{r, i}^{p}
$$

where $I_{r, j}^{s}$ is the demand for the investment good produced by sector $j$.

Public capital is accumulated by the government. Public capital in the model is not treated as a pure public good but is characterized by some degree of congestion. Hence, the public capital services available from the public capital stock $K^{g, s}$ are adjusted for congestion by aggregate production. Therefore an increase in production reduces the effective quantity 
of public capital stock enjoyable by all firms.

$$
K_{r}^{g, d}=K_{r}^{g, s}\left(\sum_{i} N_{r, i} Y_{r, i}\right)^{\gamma} \gamma \in(0,-\infty)
$$

where $\gamma$ is the congestion parameter.

Goods and services can be sold in the domestic economy or exported to other regions. Trade between regions is associated with a set of bilateral regional transportation costs. In each region aggregate demand, $X_{r, i}$, for the composite good from sector $i$ is determined by the sum of intermediate demand by all firms and all components of final demand. In perfectly competitive sectors, the composite good $i$ is based on an Armington assumption and takes the form of a CES aggregate of domestically produced goods and imported goods. In imperfectly competitive sectors, the composite good $i$ is based on a Dixit-Stiglitz specification capturing the product differentiation at the individual firm level. Normalizing the number of firms in the competitive sector to 1 then the demand by region $r$ for sector $i$ good from an individual firm in region $r^{\prime}$ under the two assumptions can be formulated identically as

$$
\frac{X_{r^{\prime}, i, r}}{\left(1+\tau_{r^{\prime}, i, r}^{t r}\right)}=\alpha_{r^{\prime}, i, r}^{x}\left[\frac{\left(1+\tau_{r^{\prime}, i, r}^{t r}\right)\left(1+\tau_{r, i}^{p}\right) P_{r^{\prime}, i, r}^{x}}{P_{r, i}}\right]^{-\sigma^{x}} X_{r, i}
$$

with the price index

$$
P_{r, i}=\left(\sum_{r^{\prime}} N_{r^{\prime}, i} \alpha_{r^{\prime}, i, r}^{x}\left(\left(1+\tau_{r^{\prime}, i, r}^{t r}\right)\left(1+\tau_{r, i}^{p}\right) P_{r^{\prime}, i, r}^{x}\right)^{1-\sigma^{x}}\right)^{\frac{1}{1-\sigma^{x}}}
$$

where $P_{r^{\prime}, i, r}^{x}$ is the price set by a firm in region $r^{\prime}$ (net of product taxes $\tau_{r, i}^{p}$ and transport costs at the net rate $\left.\tau_{r^{\prime}, i, r}^{t r}\right)$ selling to region $r$.

Due to its high dimensionality, RHOMOLO is solved following a recursively dynamic approach. It contains a sequence of short-run equilibria that are related to each other through the build-up of physical and intangible capital stocks. 
Fig. 5.3 R\&D

intensity across EU

regions

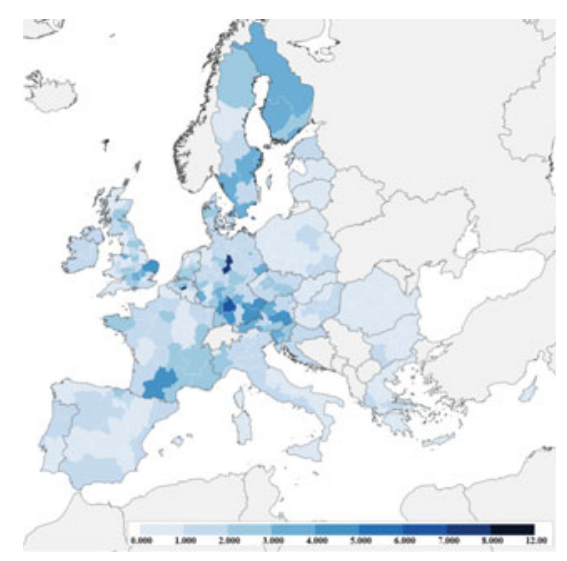

\subsubsection{RED in RHOMOLO}

The objective of the RHOMOLO model is to address regional deviations in policy impacts. The model is calibrated to the regional levels of R\&D investments observed in the reference year. Hence, the model captures the large regional differences in $\mathrm{R} \& \mathrm{D}$ expenditures across the EU. Figure 5.3 shows the geographical variations in regional R\&D intensity in the model's reference year. The highest R\&D intensities can be observed in the Belgian region Brabant Wallon and the German regions Braunschweig and Stuttgart. R\&D intensity is, respectively, 5.6, 3.6 and 3.0 times higher than the EU average. ${ }^{6}$ The figure also reveals that deviation in R\&D intensity exists within EU Member States. Most Member States contains one or several regions which are considerable more R\&D intensive relatively to the national average.

RHOMOLO captures in detail regional deviations in R\&D spending in the reference year whereas the modeling of dynamic R\&D impacts are specified in a relatively simple setup. Any changes in the R\&D investment level are introduced into the model as an exogenous shock. ${ }^{7}$ The impact of a change in $\mathrm{R} \& \mathrm{D}$ expenditures enters into the model through two

\footnotetext{
${ }^{6}$ For more perspective on regional disparities, R\&D intensity in Brabant Wallon is 19 times higher than in the regions with the lowest R\&D intensity, namely the Romanian region Sud-Est and the Autonomous Spanish region of Ceuta.

7 The current version of RHOMOLO does not include any endogenous respond to $\mathrm{R} \& \mathrm{D}$ spending in response to changes in economic activity. Hence, a change in say
} 
channels; a channel with temporary demand effects and a channel with permanent structural effects.

First, consider the temporary demand effects. The way this is introduced into the model depends on whether the R\&D expenditure is undertaken as a public R\&D activity or as a R\&D expenditure conducted by the private sector. A change in public $R \& D$ spending is associated with a change in public expenditures introduced as an exogenous public expenditure shock. Hence, a change in public R\&D expenditure affects the demand for public final consumption goods. A change in private R\&D spending is associated with a change in private investments introduced as a change in the risk premium faced by firms. A change in risk premium affects the firms' user cost of capital and hence the desired level of investments. A change in private R\&D expenditure thus affects the demand for investment goods.

Second, consider the permanent, structural effect. It is assumed that regional $\mathrm{R} \& \mathrm{D}$ spending leads to an increase in the intangible knowledge capital stock which in turn spills into an increase in TFP for all firms in the region. In the model, the impact of R\&D expenditure on TFP through the accumulated knowledge capital stock is captured by a regional R\&D elasticity $\sigma^{r d}$ defined as

$$
\sigma_{r}^{R D}=\frac{\partial \varphi_{r, t}}{\partial R \operatorname{Dexp} p_{r, t}} \frac{R \operatorname{Dexp} p_{r, t 0}}{\varphi_{r, t 0}}
$$

where $R D \exp _{r}$ is R\&D expenditure in region $r$, the subscript $t 0$ denotes value in the reference year. The $R \& D$ elasticity is conditional on $R \& D$ intensity within the region. Hence, the model allows for spatial variations in the economic impact from R\&D spending across EU regions. Higher regional R\&D intensity is associated with higher spillover from R\&D expenditure to TFP. The intuition is that firms in regions that are already spending much on $\mathrm{R} \& \mathrm{D}$ signal their pre-existing capacity to generate value from innovation activities. The deviation of TFP from the reference scenario evolves according to

$$
\varphi_{r, t}=\varphi_{r, t 0}\left(1+\sigma_{r}^{R D} \sum_{i} \frac{R D \exp _{r, t-i}-R \operatorname{Dexp} \exp _{r, t 0}}{R D \exp _{r, t 0}}\left(\frac{1}{1+\delta^{r d}}\right)^{i}\right)
$$

public investments for transport infrastructure will not lead to an endogenous change in regional $R \& D$ spending. 
where $\delta^{r d}$ is the depreciation rate of TFP for firms in region $r$.

The R\&D elasticities used in RHOMOLO are based on estimates by Kancs and Siliverstovs (2016). They estimate the relationship between R\&D investment and firm productivity growth by explicitly modelling non-linearities in the $\mathrm{R} \& \mathrm{D}$-productivity relationship. They find that the impact of R\&D investment on firm productivity is different at different levels of $\mathrm{R} \& \mathrm{D}$ intensity with the relationship between $\mathrm{R} \& \mathrm{D}$ expenditures and productivity growth being highly non-linear. Only after a certain critical mass of knowledge accumulates productivity growth becomes significantly positive. Based on the estimates by Kancs and Siliverstovs, we assign values to the R\&D elasticities for all the regions in the model. The geographical distribution is shown in Fig. 5.4. The R\&D elasticities vary from 0.008 to 0.152 . More than half of the EU regions have R\&D elasticities below 0.01 . The assumption of the non-linear nature of $\mathrm{R} \& \mathrm{D}$ impact means that regions with high $\mathrm{R} \& \mathrm{D}$ intensity in the reference year also has substantial higher R\&D elasticities. Therefore a policy of R\&D support would yield different returns across regions. However, the economic impact of R\&D support not only depends on the regional R\&D elasticity but also on the structural composition of the regional economy, factor endowments and trade patterns. Given the recursive dynamics of RHOMOLO, the parameter capturing changes in TFP for all firms in a region is updated before each model iteration.

Fig. 5.4 Regional $\mathrm{R} \& \mathrm{D}$ elasticities in RHOMOLO

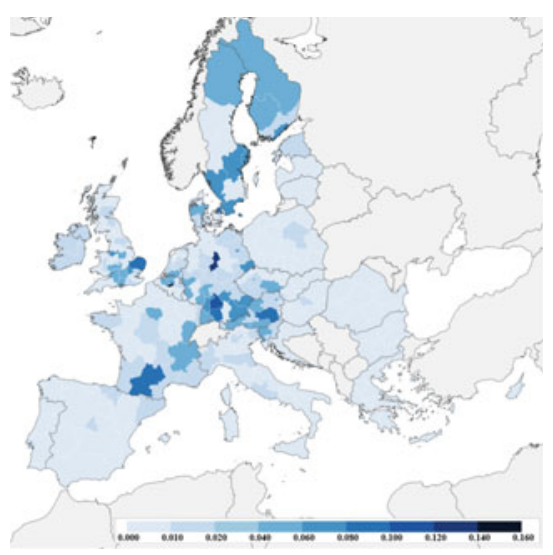




\subsubsection{Limitations}

The way R\&D impacts the economy in the current version of RHOMOLO has limitations. Firstly, changes in R\&D spending are exogenous. Hence, firms do not endogenously decide on the optimal level of R\&D investments in the model based on expected future returns.

Secondly, R\&D expenditures enter the model at a regional level with all firms benefiting equally from an improvement in TFP. Estimates from Kancs and Siliverstovs (2016) suggest that R\&D elasticities could vary substantially across sectors. The current specification of R\&D does not capture that policies targeting different sectors may impact TFP differently. Furthermore, sector-specific R\&D investments may result in improvements in TFP which mainly benefit firms in the sector conducting the R\&D activity with more limited TFP impact on firms in other sectors. ${ }^{8}$

Thirdly, the current specification does not explicitly address diffusion of technologies across regions. In the current model setting an increase in TFP in a region would benefit firms in neighbouring regions through trade due to cheaper imported intermediate inputs. Furthermore, in sectors characterized by monopoly power, a fraction of firms would reallocate to the region experiencing TFP growth. However, TFP of firms in neighbouring regions does not increase due to technology absorption. This reduces the benefit of R\&D investments across the EU.

Fourthly, the impact of public R\&D investments and private $R \& D$ investments is assumed to result in identical increases in TFP for firms within a region. Ideally, one would assign different R\&D elasticities to these two types of R\&D investments.

\subsubsection{Addressing the Limitations for RoD Modelling in RHOMOLO}

The need for assessing the regional economic impacts of $R \& D$ policies in RHOMOLO means that the way R\&D enters into the model is continuously updated and improved. Some key challenges have been identified which the modelling of R\&D in RHOMOLO should address. First, a specification that endogenizes decisions on $R \& D$ investments by private

${ }^{8}$ Although some multi-purpose technologies may improve TFP across all sectors. 
firms could be introduced into the model. This would allow public policies to affect $R \& D$ decisions in other regions. A challenge for such a specification is that the model is solved by recursive dynamics. Hence, agents current behaviour is not influenced by expectations about the economic conditions in future periods. A possible solution could be to introduce a specification which capture agents' expectations based on current or past states of the economy.

Second, to allow for sectoral differences in R\&D impact one could introduce sector-specific R\&D spending into the model. Furthermore, one could distinguish between public sector and private sector R\&D expenditure. Allowing for sector-specific R\&D spending would also allow for varying spillover effects within and across sectors. However, introducing sector-specific R\&D investments to the model significantly increase the data requirements as one would need sectoral R\&D investments at the regional level and estimated sectoral R\&D's own and cross elasticities capturing the impact of R\&D investments on TFP.

Third, a formal modelling of $R \& D$ production, which puts a higher emphasis on high-skilled labour input and high tech intermediate inputs, could be introduced. Currently, the cost of $\mathrm{R} \& \mathrm{D}$ production is defined as, respectively, the price of the public consumption composite or the price of the capital goods composite. A more formal treatment of R\&D production would also allow policies targeting education or improved labour skills to impact the cost of $\mathrm{R} \& \mathrm{D}$ production.

Fourth, a formal modelling of the linkages through which R\&D production impacts the economy could be incorporated into the model. This could be through a combination of the mechanism found in the expanding variety model originally proposed by Romer (1990) and the Schumpeterian endogenous growth model focusing on innovation-led growth and creative destruction originally proposed by Aghion et al. (1998) and Aghion and Howitt (1992).

Fifth, the model should address how technology and innovation diffuse into other sectors and regions. Several models of diffusion have been proposed in the literature (see e.g. Barro \& Sala-I-Martin, 1997; Grossman \& Helpman, 1993). One possibility would be to add the modelling of a costly process through which firms may adopt existing technologies as for example proposed by Comin and Gertler (2006). This would allow one to distinguish between the impact from policies targeting R\&D production and policies concerned with technology adoption in regions. Clearly any modelling of technology diffusion and R\&D 
spillovers across sectors and regions would need to rest on stylized facts identified in empirical studies covering data at the level of firms, regions or countries.

\subsubsection{Model Summary}

The spatial dynamic general equilibrium model RHOMOLO contains a detailed specification of regional economies and their spatial interactions. The model allows for a regional assessment of economic impacts of R\&D expenditures by the use of a relatively simple treatment of R\&D. An exogenously determined level of R\&D expenditures impacts the economy through a temporary demand channel that either raises public consumption or private investments through a permanent structural channel that leads to changes in TFP for all firms in a region. The impact of R\&D spending varies across regions as a result of variations in the composition of input demand and regional variations in the R\&D elasticity which is assumed to rise with higher R\&D intensity. However, the impact of R\&D spending also depends on regional variations in factor endowments and trade linkages. The specification of R\&D in RHOMOLO has a number of limitations including the lack of endogenous adjustment of R\&D spending and no formal modelling of technology diffusion across regions and sectors. These limitations could be addressed in future developments of the model.

\subsection{An Example: Simulating the EX-Ante Macroeconomic Impact of Horizon Europe}

Macroeconomic modelling is used by the European Commission for policy impact assessments including assessments of policies in support to Research and Innovation (R\&I). The aim of such assessments is to assist policymakers by providing an ex-ante assessment of potential outcomes of the suggested policy proposals. This section provides an example of how the dynamic Spatial Computable General Equilibrium model RHOMOLO is used to examine the economic impact of R\&I support policies. More specifically we present some of the findings of the economic impact assessment accompanying the proposal for the Horizon Europe Framework Programme. Horizon Europe is the European Commission proposal for the EU research and Innovation 
programme for 2021-2027. ${ }^{9}$ The programme aims to support the provision of European R\&I investments. Through EU-wide competition and cooperation, the programme supports training and mobility for scientists, creates transnational cross-sectoral and multidisciplinary collaborations and leverages additional public and private investments. The objective is to strengthen the scientific and technological bases of the EU and foster its competitiveness, including for its industry. The programme seeks to address particular R\&I challenges faced by the EU and to contribute to tackling global challenges, including the Sustainable Development Goals.

Substantial variations in industrial structures, infrastructure and socioeconomic conditions exist across the EU Member States at the national level and even more so at the sub-national level. Likewise, R\&I activities vary largely at the sub-national level with R\&I activities clustering in some areas leaving other areas with more modest R\&I activities. Reflecting such regional differences, the allocation of resources under Horizon Europe is likely to vary across regions. Horizon Europe may shift resources across EU regions and impact differently the various regional economies. Furthermore, structural socio-economic differences across EU regions may result in heterogeneous regional responses to public R\&I support. This calls for an impact assessment of the European R\&I support programme to also consider the sub-national level.

This section exemplifies the use of RHOMOLO for the ex-ante impact evaluation of the Horizon Europe policy scenario. A discussion of its economic impacts at both the aggregate EU level and at the regional level is provided.

\subsubsection{Scenarios and Method}

Our example is taken from the economic impact assessment accompanying the proposal for the Horizon Europe Framework Programme (see Christensen, 2018; European Commission, 2018). The proposal concerns EU support to R\&I for the period 2021-2027. More specifically, we examine the outcome of a policy scenario describing the introduction of Horizon Europe. The budget size of the Horizon Europe scenario is assumed to be identical to the programme it replaces (Horizon 2020) in constant prices, minus the contribution from the UK (assumed to be $15 \%$

\footnotetext{
${ }^{9}$ It replaces the current Framework Programme Horizon 2020 which will expire by the end of 2020 .
} 
of the budget). The impact assessment thus considers total cumulative spending of approximately 70 billion which is equivalent to $0.5 \%$ of GDP in 2017 for the EU excluding the UK. ${ }^{10}$ In the Horizon Europe scenario, we assume that public support to R\&I generates a further rise in private R\&I spending through a direct leverage effect. In the impact assessment we assume a direct leverage effect of $9.75 \%$ which is a weighted average of the direct leverage effect of respectively basic research and applied research suggested by Boitier et al. (2018). Their suggested leverage effects take outset in a survey on research units involved in the 7 th Framework Programme and empirical estimates in the literature.

The outcome of the Horizon Europe scenario is compared to a reference scenario without Horizon Europe. Instead, the EU Member States spend an amount identical to their Horizon Europe contribution on public investments including national R\&I support programmes. Spending by the Member States is financed by lump sum taxes. We assume that the regional allocation of the additional public investments follows the regional allocation of current public investments within the Member States. Public spending for national R\&I support is assumed to follow the same regional allocation within each Member State as of the current EU R\&I support programme (Horizon 2020). Given these assumptions, substantial variations exist in the regional allocation of respectively public investments and public R\&I support in the reference scenario. While public investments are spread out across regions within the Member States, the regional allocation of public R\&I support is concentrated in R\&I intensive metropolitan regions (Figs. 5.5 and 5.6). We assume that the introduction of Horizon Europe involves a reduction in public investments and in national public support to R\&I which is paid as contribution to Horizon Europe and distributed across EU regions as public support to R\&I. The regional allocation of EU-wide support to R\&I is assumed to be identical to the regional allocation of Horizon 2020.

Given these assumptions, large regional variations in EU R\&I support can be observed. The largest recipient of accumulated public spending

${ }^{10}$ After the impact assessment was carried out the proposed budget by the European Commission for Horizon Europe has been increased to 94.1 billion. In addition to the Horizon Europe's 2021-2027 Framework Programme the proposed European Commission R\&I support programme also includes the 2021-2025 Research and Training programme of the European Atomic Energy Community (the Euratom Programme) with a proposed budget of 2.4 billion and 3.5 billion allocated under the InvestEU fund. 
Fig. 5.5 Additional public investments in reference scenario (\% of GDP)

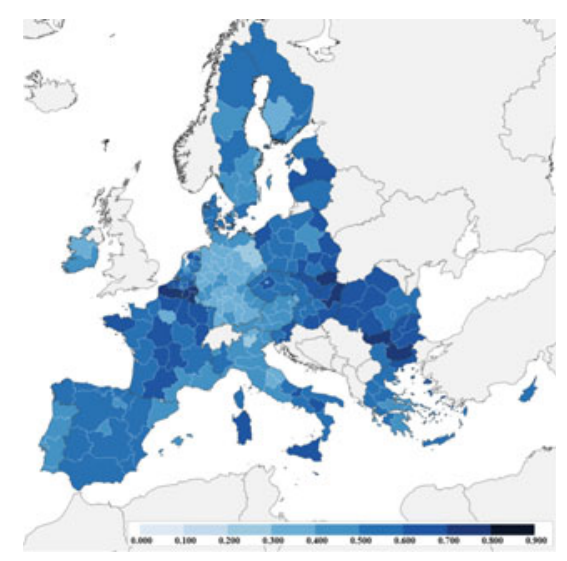

Fig. 5.6 Additional national public R\&I support in reference scenario (\% of GDP)

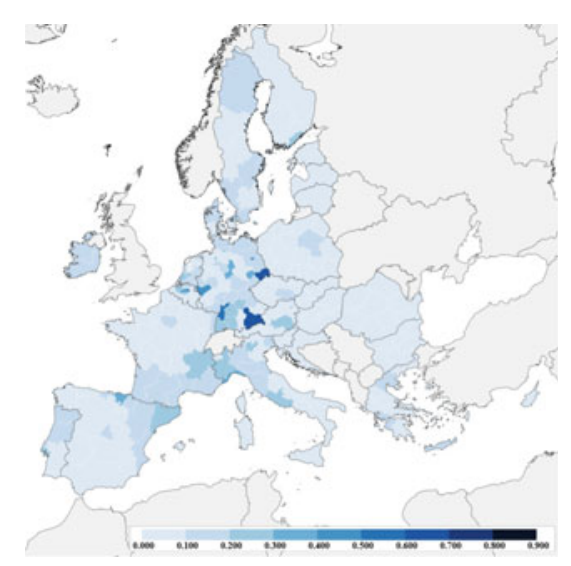

for R\&I support during the programme period is Île-de-France $(5,900$ million) followed by Oberbayern (3,600 million). Other large recipients of public spending are Rhône-Alpes (2,300 million), Cataluña (2,000 million), Lombardia (2,000 million) and Lazio (2,000 million) as illustrated in Fig. 5.7.

Considering the regional allocation of cumulative EU spending in support for R\&I relative to the size of the regional economy also reveals that R\&I support is concentrated in metropolitan regions. In percent of GDP in the RHOMOLO model's base year (2013) the largest recipients 
Fig. 5.7 EU support for R\&I in Horizon Europe scenario (million euro)

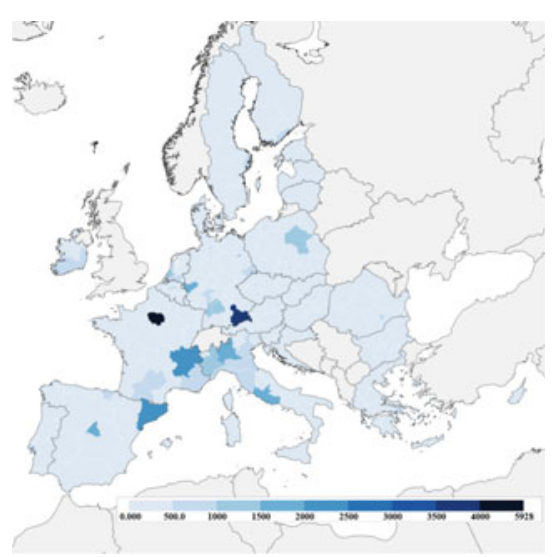

of cumulative public spending in support to R\&I over the programme period is assumed to be the Belgian regions of Brussels (1.9\% of base year GDP) and Vlaams-Brabant (1.7\% of base year GDP). This is followed by Dresden (1.7\% of base year GDP), Oberbayern (1.6\% of base year GDP), País Vasco (1.5\% of base year GDP), Bucharest (1.5\% of base year GDP) and Bratislava (1.5\% of base year GDP). The geographical allocation is illustrated in Fig. 5.8.

Differences in regional allocation of respectively public investments and public expenditures for R\&I support change the net allocation of

Fig. 5.8 EU support for R\&I in Horizon Europe scenario (\% of GDP)

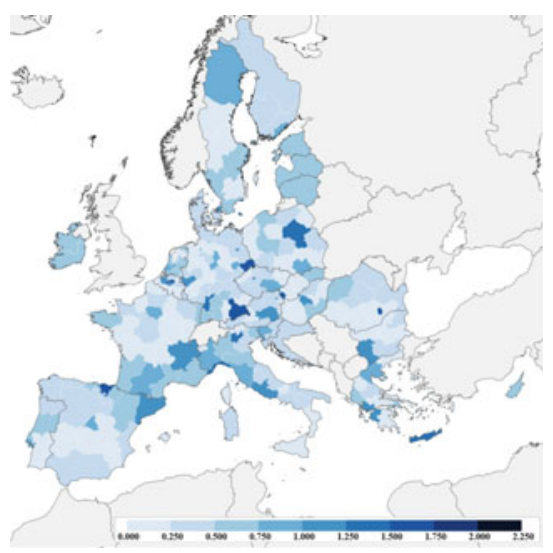


public spending across EU regions following the introduction of Horizon Europe. With the introduction of Horizon Europe all regions experience a rise in public R\&I support, however, the bulk of the increase is concentrated in the R\&I intensive regions. As a result, the net allocation of public spending received by each region varies. The R\&I intensive regions experience a net gain as the rise in public R\&I support outweighs the decline in public investments whereas the less R\&I intensive regions experience a net decline in public spending as the decline in public investments outweighs the rise in public R\&I support. This is illustrated in Fig. 5.9 which shows the net change in public spending received by each region following the introduction of Horizon Europe. Although a region experiences a net decline in public spending following the introduction of Horizon Europe, it may still benefit from the EU R\&I programme through trade linkages with neighbouring regions and from improved productivity resulting from higher R\&I investments.

The reference scenario and the Horizon Europe policy scenario are simulated on the most recent version of RHOMOLO described in Lecca et al. (2018), with the R\&D sector as described in the previous section. R\&I expenditure is modelled as private investments. Public expenditure in support for R\&I is introduced into the model as a reduction in user cost of capital which, in turn, generates an increase in private sector R\&I investments. Hence, public spending in support to R\&I generates demand for capital goods. In addition, R\&I expenditure leads to accumulation of an intangible knowledge capital stock which, in turn, spills

Fig. 5.9 Change in public spending following the introduction of Horizon Europe (\% of GDP)

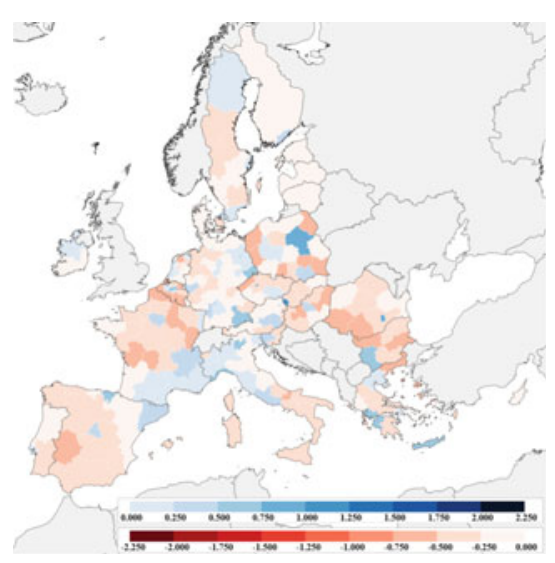


into an increase in TFP. The impact of R\&I expenditure on TFP through the accumulated knowledge capital stock is captured by a set of regional spillover elasticities which are conditional on R\&D intensity within the region. Higher regional R\&D intensity is associated with higher spillover from knowledge capital to TFP. The intuition is that firms in regions that are already spending much on R\&D signal their pre-existing capacity to generate value from innovation activities. The R\&D spillover elasticities are based on estimates by Kancs and Siliverstovs (2016). The model is solved by recursive dynamics.

\subsubsection{Economic Impact at Aggregate EU Level}

We begin by considering the aggregate economic impact for the EU excluding the UK (for simplicity we will refer to this as EU). Results are presented as deviations from the reference scenario.

It is assumed that the EU R\&I programme is financed by a reallocation of public spending by each Member State from domestic public investments and national public R\&I support towards contributions to Horizon Europe. In RHOMOLO such a shift in policy would mainly affect the economy through two channels; a demand channel and a productivity channel. First, consider the demand channel. Introducing Horizon Europe leads to a rise in EU public spending for R\&I support which is partly offset by a decline in national public spending for R\&I support. The net effect is an increase in private R\&I investments which raises private demand for capital goods. Resources are being reallocated from public investments within the regions which reduce the public demand for capital goods. How this shift in spending strategy effects the aggregate demand in a region depends on the combined net effects from the decline in regional public investment and the rise in R\&I investments. Aggregate demand is also affected by the composition of inputs (material inputs and factor inputs) used in the production of the composite capital good demanded by respectively the private R\&I investors and the government. This would depend on the sectors from which the material inputs are sourced, how much of these sectors' input that is produced domestically and how much that is imported, and on the share of the various domestic production factors used in the production of the capital goods. For example, a shift in investment demand towards capital goods with a higher domestic input share and a higher share of factor inputs would, all else equal, increase domestic production and household income. Second, 
consider the productivity channel. A rise in private R\&I investments leads to higher knowledge accumulation which, in turn, generates a rise in TFP. In contrast, a lower public capital accumulation is assumed to generate a negative productivity effect through which public capital services bring reduced efficiency to the private production sectors in the region.

Figure 5.10 shows the change in EU GDP relative to the reference scenario. The introduction of Horizon Europe leads to a gradual rise in EU GDP. This is mainly determined by higher TFP growth which outweighs the lower productivity growth caused by the reduction in public investments. The largest deviation in EU GDP occurs in 2029 where EU GDP is $0.2 \%$ higher than the reference scenario. The long-run GDP impact of introducing the EU R\&I support programme is more modest. Horizon Europe runs until 2027 after which it is assumed that EU R\&I support stops. In the RHOMOLO model, an efficiency gain from the accumulated knowledge stock is assumed to depreciate. Hence, TFP gains from R\&I investments made in the past gradually die out.

Table 5.1 shows the cumulative EU GDP deviation relative to the reference scenario. The introduction of Horizon Europe results in cumulative EU GDP in 2040 to become $0.1 \%$ higher than in the reference scenario. The increase in cumulative EU GDP in 2050 is slightly less due to the depreciation of TFP gains.

The deviation of EU GDP relative to the reference scenario can be decomposed into macroeconomic aggregates. This is shown in Fig. 5.11. The introduction of the EU R\&I support programme causes a temporary

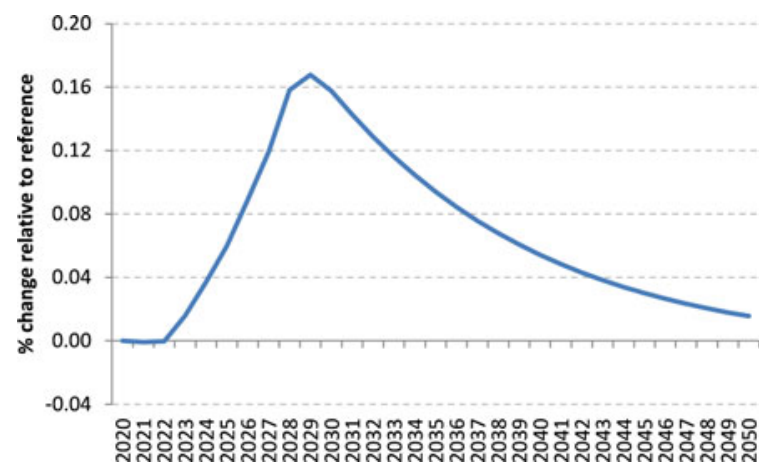

Fig. 5.10 Change in EU GDP (\% relative to reference scenario) 
Table 5.1 Deviation of EU GDP (\% relative to reference scenario)

\begin{tabular}{ll}
\hline & $\begin{array}{l}\text { Impact of EU REI } \\
\text { programme }\end{array}$ \\
\hline $\begin{array}{l}\text { Cumulative EU GDP deviation in } \\
2030\end{array}$ & 0.063 \\
$\begin{array}{l}\text { Cumulative EU GDP deviation in } \\
2040\end{array}$ & 0.071 \\
Cumulative EU GDP deviation in \\
2050
\end{tabular}

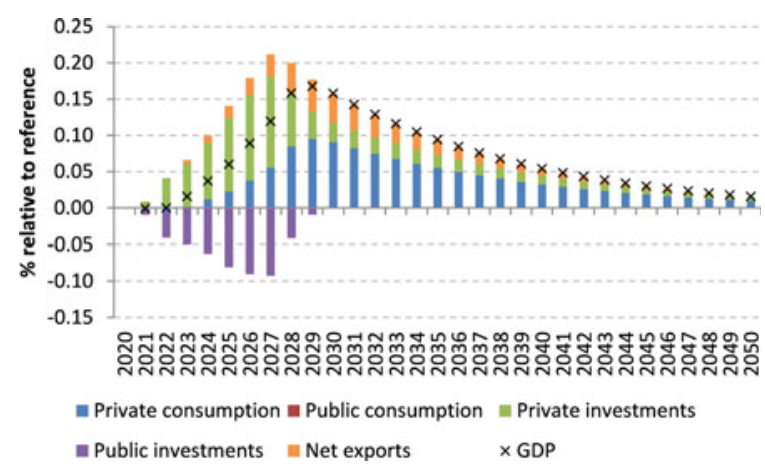

Fig. 5.11 Contribution to change in EU GDP (\% relative to reference scenario)

decline in public investments in the EU Member States in the period 2021-2029. Private R\&I investments rise and this contributes the most to the overall increase in EU GDP relative to the reference scenario. The introduction of the EU R\&I support programme also leads to a rise in private household consumption and a rise in net exports. From 2030 the rise in private household consumption contributes the most to the change in EU GDP. Higher productivity growth results in an improvement of the EU trade balance, private investments and consumption opportunities for EU households.

The introduction of Horizon Europe stimulates EU medium to long term employment. This is illustrated by Fig. 5.12 that shows the change in EU employment relative to the reference scenario. At first the shift in spending from public investments towards R\&I support leads to a small decline in employment as the production of public capital goods is more labour intensive. The initial decline in EU employment peaks in 2022 


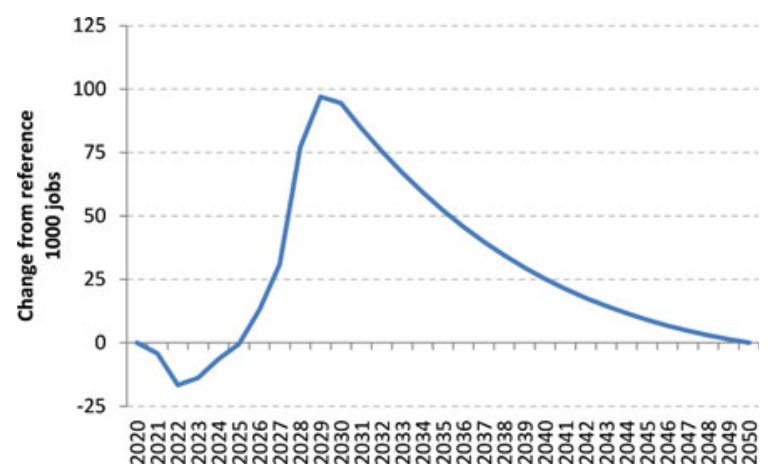

Fig. 5.12 Change in EU employment

where it is 17,000 jobs lower than in the reference scenario. However, gradually EU employment increases as a result of higher TFP growth which improves competitiveness. EU employment is at its highest in 2029 where employment is 97,000 jobs higher than the reference scenario. Long-term EU employment returns to the level of the reference scenario.

Table 5.2 shows the average EU employment deviation in 1000 jobs. Horizon Europe results in a rise in average EU employment for the period 2021-2040 of 40,000 jobs per year. The introduction of the EU R\&I support programme has a persistent impact on EU employment. For the period 2021-2050, the rise in average EU employment is 30,000 jobs per year.

Table 5.2 Average EU employment deviation

\begin{tabular}{cc}
\hline & $\begin{array}{c}\text { Impact of EU RéI } \\
\text { programme }\end{array}$ \\
\hline Average EU GDP deviation & 27.9 \\
2020-2030 & \\
Average EU GDP deviation & 40.1 \\
2020-2040 & \\
Average EU GDP deviation & 29.9 \\
2020-2050 & \\
\hline
\end{tabular}




\subsubsection{Economic Impact at Regional Level}

The results discussed so far have considered changes in EU aggregates. However, RHOMOLO further allows for an assessment of the economic impact at the regional level. The allocation of spending for R\&I support varies across regions. Furthermore, regions vary in industrial structure, trade patterns and composition of production factors. Hence, regions may be impacted differently by the introduction of Horizon Europe. We, therefore, also consider the regional impact of Horizon Europe.

The regional impact on GDP and Employment from the introduction of Horizon Europe can be examined in a box plot as shown in Fig. 5.13. The box plot provides a display of the distribution of the regional deviation in respectively cumulative GDP in 2040 and cumulative employment in 2040. The central rectangle spans the first quartile to the third quartile with the small horizontal line inside the rectangle showing the median. The vertical line that extends from the top of the rectangle indicates the maximum value of regional impact, and the vertical line that extends from the bottom of the rectangle indicates the minimum value of regional impact.

The introduction of the EU R\&I support programme results in a rise in cumulative EU GDP in 2040. However, as shown in the box plot, considerable divergence exists in regional GDP impact. Less than half of the regions experience a rise in cumulative GDP in 2040. The span from the third quartile to the maximum value is higher than the span from the minimum value to the first quartile. This is due to a small

Fig. 5.13 Change in regional GDP and employment (\% relative to reference scenario)

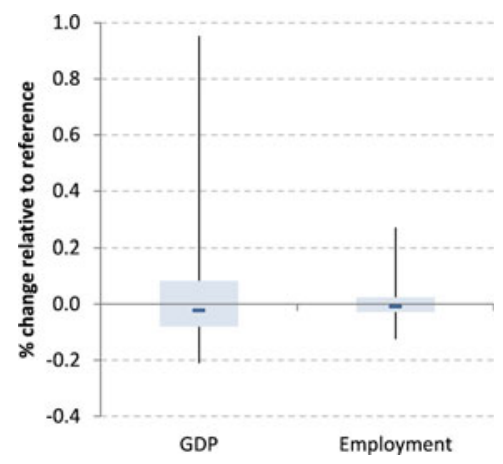


Fig. 5.14 Change in regional GDP (\% relative to reference scenario)

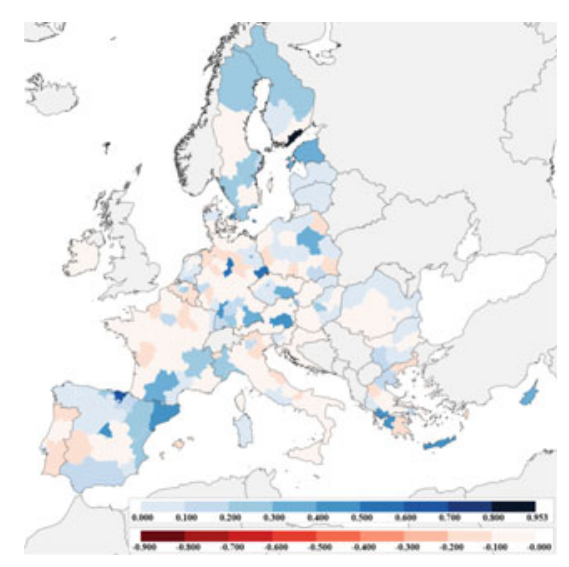

number of regions which experience relatively large increases in cumulative GDP. Horizon Europe causes a shift from public investments to private R\&I investments. This results in a rise in regional TFP growth and a decline in public capital services. However, the changes in spending are not evenly distributed across regions. Some regions experience large increases in public expenditures in support to R\&I others suffer from decline in public investments that are allocated to the regions. The shift in demand and productivity gains across regions lads to changes in relative prices. Therefore, as a result of the shift in spending strategy, some regions experience a decline in GDP while other regions gain. Horizon Europe also results in considerable regional variations in employment impact. As illustrated in the box plot the number of regions that suffer from a decline in employment outnumber the regions benefitting from an improvement in employment. More specifically, Horizon Europe results in a rise in cumulative employment in 2040 for 90 regions and a reduction in employment for 140 regions. ${ }^{11}$ As can be seen in the box plot, a small number of regions experience relatively large increases in cumulative employment due to the introduction of the EU R\&I support programme.

Figure 5.14 shows the geographical distribution of cumulative regional GDP deviation in 2040 following the introduction of Horizon Europe. We observe that the rise in cumulative GDP is more prominently in regions that are large recipient of public spending in support for

${ }^{11}$ Excluding the UK reduces the number of EU regions in the model to 230. 
R\&I. Generally, these regions would experience higher TFP growth and improved competitiveness leading to a rise in GDP. The largest increase in GDP is found in the Finnish region of Helsinki-Uusimaa where cumulative GDP in 2040 is $1.0 \%$ higher than in the reference scenario. Other regions that experience some of the largest increases in GDP are the Spanish region of País Vasco $(0.6 \%)$ and the German region of Dresden $(0.5 \%)$. In contrast, other regions attract less of the public R\&I support spending and suffer from the decline in public investments which results in a decline in cumulative GDP. The largest decline in cumulative GDP occurs in the autonomous Spanish regions Ceuta $(-0.2 \%)$ and Melilla $(-0.2 \%)$. The introduction of Horizon Europe results in a rise in GDP in 97 regions and a decline in GDP in 133 regions relative to the reference scenario.

In Fig. 5.15 we explore the relationship between the cumulative deviation in public spending in support to R\&I and the cumulative deviation in GDP in 2040 for all EU regions. The figure reveals a positive relationship between public spending in support to R\&I and the change in cumulative GDP. The higher the rise in public spending in support to R\&I the higher the rise in GDP. However, the change in GDP also depends on other regional characteristics such as differences in industry structures, the mix of factor inputs and trade patterns which affects the relative change in competitiveness relative to main trading partners. The figure shows that regions which experience a small increase in public support

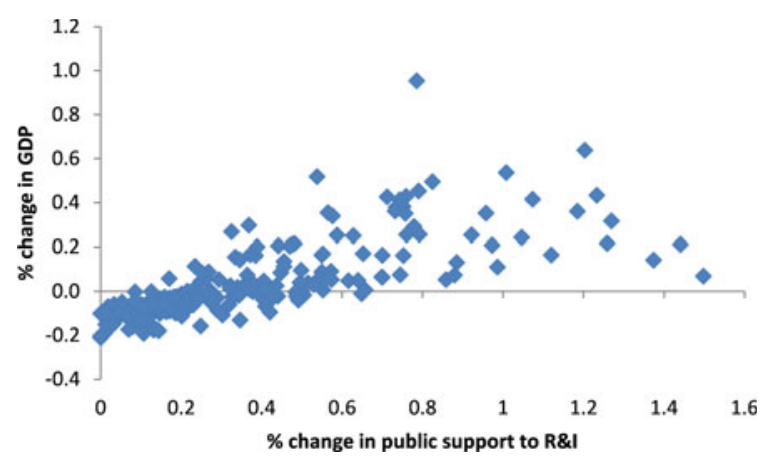

Fig. 5.15 Relationship between the deviation of cumulative public support (EU and national) to R\&I and cumulative regional GDP deviation in 2040 (\% change from reference scenario) 
Fig. 5.16 Change in

regional employment $(\%$

relative to reference

scenario)

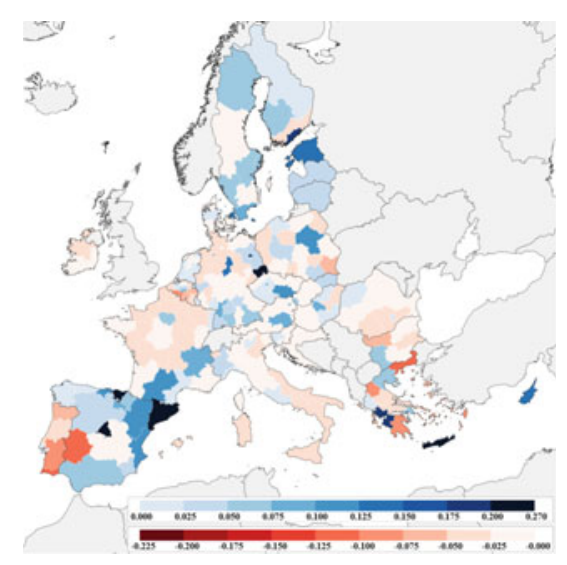

to R\&I generally suffer a small decline in cumulative GDP relative to the reference scenario. In the analysis, Horizon Europe is assumed to be financed by Member States' contributions taken from public investments and national R\&I programmes. Within each Member State, resources for public investments are allocated differently than the regional allocation of public R\&I support. Hence, regions which are allocated small shares of the public spending in support to R\&I may suffer from a decline in public spending allocated to the region. For these regions, the impact from a decline in public investments outweighs the impact from a rise in public spending for R\&I support. In contrast, regions receiving a large share of public support to R\&I are associated with higher cumulative GDP relative to the reference scenario. For these regions, the impact from a rise in public spending to R\&I support outweighs the impact from lower public investments.

Figure 5.16 shows the geographical distribution of the regional changes in cumulative employment in 2040 relative to the reference scenario. The largest rise in employment can be found in regions which are among the largest recipients of EU spending in support to R\&I and, at the same time, also have relatively high unemployment rates, which gives potential for employment growth. ${ }^{12}$ The largest rise in employment

12 The impact assessment is conducted on a version of RHOMOLO in which net migration between regions is held constant and household labour supply is exogenous. Hence, a rise in employment can only arise from a reduction in the unemployment rate. 


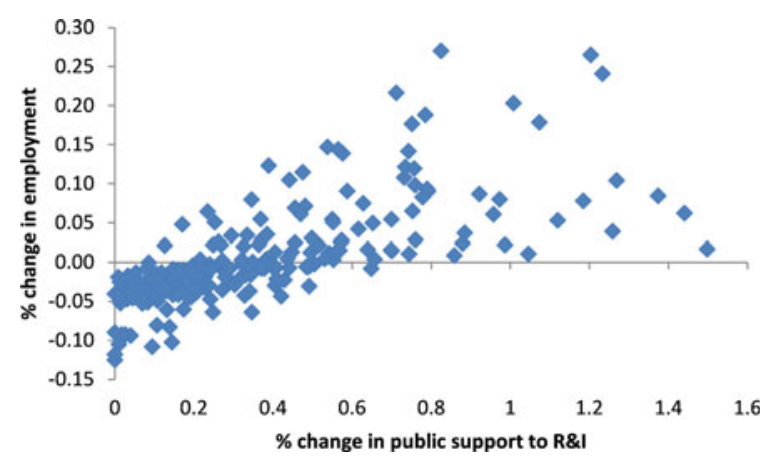

Fig. 5.17 Relationship between the deviation of cumulative public support (EU and National) to R\&I and cumulative regional employment deviation in 2040 (\% change from reference scenario)

occurs in the Spanish region of Cataluña where cumulative employment in 2040 is $0.3 \%$ higher than in the reference scenario. The largest decline in cumulative employment can be found in the two autonomous Spanish regions Ceuta $(-0.1 \%)$ and Melilla $(-0.1 \%)$ who suffers from the decline in national public investments.

In Fig. 5.17 we explore the relationship between the cumulative deviation in public spending in support to R\&I and the cumulative deviation in Employment in 2040 for all the EU regions. The figure reveals a positive relationship between public spending in support to R\&I and the change in cumulative employment. However, the change in employment also depends on other regional characteristics which affect the demand for labour such as differences in labour intensity in production, skills composition, regional unemployment rates, industry structures and trade patterns which affect the relative change in competitiveness relative to main trading partners. For example, the regions benefiting from the largest rise in public support to R\&I are not the regions with the largest rise in employment.

\subsubsection{Summary}

This section presents findings from the economic impact assessment accompanying the European Commission proposal for the Horizon Europe Framework Programme. The impact assessment compares the 
outcome of a policy scenario with Horizon Europe to a reference scenario in which an identical amount of resources are spent by the Member States on public investments and national R\&I support programmes. The economic impact is evaluated at the aggregate EU level and at the regional level. Results show that the EU R\&I programme contributes to GDP growth and employment in the EU. In 2040 the cumulative EU GDP would be $0.1 \%$ higher than in the reference scenario. The deviation of total EU employment is at its maximum in 2029 where employment would be 97,000 jobs higher than the reference scenario. For the period 2021-2040, EU employment would on average be 40,000 jobs per year higher than in the reference scenario.

However, considerable regional variations in economic impact emerge. Shifting resources from public investments and national R\&I support programmes to the EU R\&I support programme mainly benefits the most R\&I intensive regions in the EU who are the large receivers of EU spending in support to R\&I. These regions experience an increase in TFP growth and an improvement in competitiveness leading to a rise in GDP and employment. We find that cumulative GDP in 2040 increases up to $1.0 \%$ and cumulative employment in 2040 rises up to $0.3 \%$ relative to the reference scenario. However, the regional impact on GDP and unemployment is unevenly distributed across EU regions. About $60 \%$ of all regions experience a decline in cumulative GDP and employment following the change in policy. These regions suffer from the reallocation of public spending from public investments and national R\&I support to EU-wide R\&I support. The declines in cumulative GDP in 2040 are up to $0.2 \%$ relative to the reference scenario while the declines in cumulative employment are up to $0.1 \%$ relative to the reference scenario.

The variations in regional economic impacts are largely resulting from assumptions concerning allocations of R\&I support across regions. In addition, regional impacts are influenced by regional variations in $R \& D$ elasticities which in RHOMOLO are conditional on regional R\&D intensity, on trade linkages and on the regional economic conditions such as the sectoral composition and labour market characteristics. Horizon Europe aims to support the provision of European R\&I investments through EU-wide competition and cooperation programme support. In the impact assessment, it is assumed that the R\&I intensive regions are able to attract an identical share of funds as in the previous EU R\&I support programme. A large proportion of funding is, therefore, allocated to the most R\&I intensive regions. 
Although our results show that about $60 \%$ of the regions experience a decline in GDP and employment following the implementation of Horizon Europe, it may still be the case that these regions potentially could benefit from the higher growth in their R\&I intensive neighbouring regions. Firstly, Member States may use public policies and fiscal transfers to redistribute the higher income in R\&I intensive regions across all domestic regions. This could compensate households in the regions suffering from the decline in public investments. Secondly, diffusion of technologies may ensure that TFP increases in R\&I intensive regions benefits neighbouring regions. In the simulation analysis, productivity gains from higher knowledge creation in the R\&I intensive regions spills into other regions through trade linkages. However, the model simulation does not explicitly address the effects from diffusion of technologies across regions. Hence, interregional spillovers from productivity increases in a region may be underestimated. Thirdly, Horizon Europe is supplemented by other EU programmes which aim to strengthen economic and social cohesion. Programmes such as the European Regional Development Fund, the Cohesion fund and the European Social fund may help address regional imbalances and promote faster dissemination and uptake of R\&I results across regions. Such synergies are not examined in the impact assessment.

\section{REFERENCES}

Aghion, P., Harris, C., \& Vickers, J. (1998). Endogenous Growth Theory. Cambridge, MA: MIT Press.

Aghion, P., \& Howitt, P. (1992). A model of growth through creative destruction. Econometrica, 60, 323-351.

Barro, R. J., \& Sala-I-Martin, X. (1997). Technological Diffusion, Convergence, and Growth. Journal of Economic Growth, 2, 1-27.

Boitier, B., P. Le Mouël, P. Zagamé, R. Winjes, P. Mohnen, A. Ricci, H. Brozaitis, J. Espasa, and V. Stanciauskas (2018). Support for the assessment of socio-economic and environmental impacts (SEEI) of European R\&I programmes: the case of Horizon Europe. Technical report, European Commission. Luxembourg: Publications Office of the European Union. ISBN 978-92-79-92736-2.

Christensen, M. (2018). Assessing the regional socio-economic impact of the European R\&I programme. JRC Working Papers on Territorial Modelling and Analysis No. 05/2018, European Commission, Seville, 2018, JRC114347. 
Comin, D., \& Gertler, M. (2006). Medium-Term Business Cycles. American Economic Review, 96, 523-551.

European Commission (2018). Commission Staff Working Document: Impact Assessment. SWD(2018) 307 final, Part 2/3 . Brussels, 7.6.2018.

Grossman, G. M., \& Helpman, E. (1993). Innovation and Growth In the Global Economy. MIT press.

Kancs, D., \& Siliverstovs, B. (2016). R\&D and Non-linear Productivity Growth. Research Policy, 45, 634-646.

Lecca, P., J. Barbero-Jimenez, M. Christensen, A. Conte, F. Di Comite, J. Diaz Lanchas, O. Diukanova, G. Mandras, D. Persyn, and S. Sakkas (2018). RHOMOLO V3: A Spatial Modelling Framework. JRC Technical Reports 111861, Publications Office of the European Union, Luxembourg.

Romer, P. M. (1990). Endogenous Technological Change. Journal of Political Economy, 98, 71-102.

Open Access This chapter is licensed under the terms of the Creative Commons Attribution 4.0 International License (http://creativecommons.org/licenses/ by $/ 4.0 /)$, which permits use, sharing, adaptation, distribution and reproduction in any medium or format, as long as you give appropriate credit to the original author(s) and the source, provide a link to the Creative Commons license and indicate if changes were made.

The images or other third party material in this chapter are included in the chapter's Creative Commons license, unless indicated otherwise in a credit line to the material. If material is not included in the chapter's Creative Commons license and your intended use is not permitted by statutory regulation or exceeds the permitted use, you will need to obtain permission directly from the copyright holder.

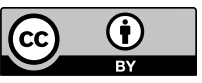

